\title{
Gender differences in conference presentations: a consequence of self-selection?
}

Women continue to be under-represented in the sciences, with their representation declining at each progressive academic level. These differences persist despite long-running policies to ameliorate gender inequity. We compared gender differences in exposure and visibility at an evolutionary biology conference by attendees at two different academic levels: student and post-PhD academic. Despite there being almost exactly a 1:1 ratio of women and men attending the conference, we found that when considering only those who presented talks, women spoke for far less time than men of an equivalent academic level: on average student women presented for $23 \%$ less time than student men, and academic women presented for $17 \%$ less time than academic men. We conducted more detailed analyses to tease apart whether this gender difference was caused by decisions made by the attendees or through bias in evaluation of the abstracts. At both academic levels, women and men were equally likely to request a presentation. However, women were more likely than men to prefer a short talk, regardless of academic level. We discuss potential underlying reasons for this gender bias, and provide recommendations to avoid similar gender biases at future conferences. 

a consequence of self-selection?

6 1. Department of Zoology, University of Melbourne, Australia

7 2. Centre for Integrative Ecology, School of Life and Environmental Sciences, Deakin University, Australia

8 3. Research School of Biology, Australian National University, Australia

9 4. Centre for Tropical Biodiversity and Climate Change, School of Marine and Tropical Biology, James Cook

$10 \quad$ University, QLD 4811, Australia

11 * Author for Correspondence

12 Dr Therésa Jones

13 The Department of Zoology, The University of Melbourne

143010 Victoria, Australia

15 Email: theresa@unimelb.edu.au

16 Tel: $+61(0) 390359576$ 


\section{Abstract}

18 Women continue to be under-represented in the sciences, with their representation declining at 19 each progressive academic level. These differences persist despite long-running policies to 20 ameliorate gender inequity. We compared gender differences in exposure and visibility at an 21 evolutionary biology conference by attendees at two different academic levels: student and post$22 \mathrm{PhD}$ academic. Despite there being almost exactly a 1:1 ratio of women and men attending the 23 conference, we found that when considering only those who presented talks, women spoke for far 24 less time than men of an equivalent academic level: on average student women presented for $23 \%$ 25 less time than student men, and academic women presented for $17 \%$ less time than academic 26 men. We conducted more detailed analyses to tease apart whether this gender difference was 27 caused by decisions made by the attendees or through bias in evaluation of the abstracts. At both 28 academic levels, women and men were equally likely to request a presentation. However, women 29 had a weaker preference for a long talk than men, regardless of academic level. We discuss 30 potential underlying reasons for this gender bias, and provide recommendations to avoid similar 31 gender biases at future conferences. 
Introduction

33 Gender discrepancies are present in many academic disciplines including science, engineering,

34 the arts, humanities, and even gender studies, despite efforts to counter them (Hill, Corbett and St

35 Rose 2010, Kretschmer, Kundra, Beaver et al. 2012). To some extent, these differences are driven

36 by perception biases and/or discrimination. For example, women are cited less often (Davenport

37 and Snyder 1995, Ferber and Brun 2011, Maliniak, Powers and Walter 2013), receive fewer

38 awards and prizes (Lincoln, Pincus, Koster et al. 2012), and have research that is valued less

39 highly than men (Davenport and Snyder 1995, Wenneras and Wold 1997, Bornmann and Daniel

40 2005, Knobloch-Westerwick, Glynn and Huge 2013), even when relative opportunity is

41 accounted for. In a recent experimental study involving students, men were evaluated as being

42 more competent and worthy of a higher starting salary than women (Moss-Racusin, Dovidio,

43 Brescoll et al. 2012). This suggests that perception biases may contribute to gender disparity

44 from even the earliest stages of a career. However, gender discrepancies are also influenced by

45 innate gender differences in behaviour. For example, women tend to publish less ( $\underline{\text { Symonds, }}$

46 Gemmell, Braisher et al. 2006, Conley and Stadmark 2012, Larivière, Ni, Gingras et al. 2013),

47 use more tentative language (Leaper and Robnett 2011), and ask for less when negotiating their

48 salary (Tinsley, Cheldelin, Schneider et al. 2009).

49

50 named after the American feminist critic Matilda Gage, who first described it, refers to the

51 systematic under-recognition and denial of the contributions made by women in science,

52 technology, engineering and mathematics (Rossiter 1993, Knobloch-Westerwick, Glynn and

53 Huge 2013); and (2) the 'leaky pipeline', which describes the dramatic reduction in the

54 proportion of women compared to men surviving each step up the academic (or equivalent)

55 ladder (Pell 1996, Winkler, Tucker and Smith 1996). The underlying reasons for the presence of

56 the Matilda effect and the leaky pipeline are diverse, complex and largely unresolved.

57 Identification and evaluation of gender discrepancies are often based on easily obtainable

58 metrics, such as the number of publications, citations, or grants received. However, important

59 dimensions of gender inequality may be overlooked by these assessments (West, Jacquet, King et

60 al.2012). One important metric, which may either directly or indirectly influence the perceived

61 quality of a researcher, is their 'visibility' within their discipline or respective community

62 (Damschen, Rosenfeld, Wyer et al. 2005, Thelwall, Barjak and Kretschmer 2006, Faulkner 2009, 
63 Schroeder, Dugdale, Radersma et al. 2013). In addition to publications and grant success,

64 visibility may be achieved through conference attendance, presentations, plenary talks, and 65 engagement with the media.

66 Recent studies present convincing evidence for consistent gender bias (favouring men) in 67 terms of conference visibility. Using 21 years of annual meeting data for the American 68 Association of Physical Anthropologists, Isbell and colleagues (2012) showed that men continue 69 to dominate conference visibility, despite the fact that women comprise the majority of their 70 membership. Men were more likely than women to request a talk in preference to a poster, and 71 men requesting a talk were more likely than women to be allocated one (rather than a poster). 72 Similarly, at the 2011 European Society for Evolutionary Biology congress (Schroeder, Dugdale, 73 Radersma et al. 2013), women were significantly under-represented among invited speakers, in 74 part because they were more likely than men to turn down invitations to present. Studies have 75 also shown that representation of women in symposia is positively related to the number of 76 women on the organising committee (Isbell, Young and Harcourt 2012, Casadevall and 77 Handelsman 2014).

78 These studies demonstrate that women currently have reduced exposure and visibility at 79 conferences compared to men. Furthermore, they highlight the complex interplay between peer 80 evaluation (Matilda effect) and a degree of active choice by women (either through their selection 81 of a poster over an oral presentation, or by their declining an invitation to speak) that perpetuate 82 these gender discrepancies. We note that the reasons for declining invitations to present are, in 83 themselves, likely to be complex and diverse, and have been covered in detail by Schroeder et al 84 (2013). None of the above studies discriminated between academics (post-doctoral researchers 85 and beyond) and students (Honours, Masters and PhD students). This distinction is important 86 because gender-specific behaviour in conference participation may differ depending on academic 87 level, and knowledge of such variation might be important in addressing gender bias.

88 Here, we use data from the 2013 Australasian Evolution Society (AES) conference, to 89 assess gender bias in conference visibility at two different academic levels: student (Honours, 90 Masters and PhD students) and academic (post-PhD). We first consider overall gender differences 91 in conference visibility (i.e., the length of time men and women from the two academic levels 92 spent presenting their research), and then use more detailed analyses to identify the source of any 93 gender differences. The conference was unusual in two respects. First, it only offered oral 94 presentations (short or long) and thus each presenter knew the amount of exposure they could 
95 expect a priori. Second, the sex-ratio of attendees was almost equal. Consequently, we should

96 anticipate that on average women and men would receive roughly equal exposure. However, we

97 found this was not the case. We narrow down the source of this gender difference, discuss the 98 possible reasons causing it, and offer advice to future conference organisers as to how to 99 encourage gender equality in visibility and exposure at their conferences. We hope that our study 100 provides a useful template with which conference organisers and attendees can assess gender bias 101 at future conferences. All authors attended this conference and two (MRES and KVF) were on 102 the abstract selection committee.

\section{Methods}

\section{Data Collection}

105 Four plenary speakers (two women, two men) accepted the committee's invitation to speak at the 1062013 Australasian Evolution Society (AES) conference. All other speakers were accepted through 107 an open process of abstract submission. At the time abstracts were submitted, delegates who 108 wished to present ( $\mathrm{N}=108 / 139$; Table 1) were asked to (1) nominate whether they preferred to 109 give a long talk (12 mins) or a short 'speed' talk (5 mins), and (2) specify whether they were a 110 student (i.e., had not had their PhD conferred) for the purposes of student awards. A selection 111 committee comprising three men and three women evaluated all requests and allocated them 112 according to the provided abstract, with all delegates who requested a talk receiving one. 113 However, conference time constraints resulted in a small number of delegates who requested a 114 long talk being allocated a short talk (Table 1). The committee's evaluations were not carried out 115 blind to author(s) or career stage (student or academic). The gender of all delegates was identified 116 post hoc (but prior to our analyses). No participant was identified in our study. Ethical approval 117 was not required for the study as both the abstracts of all speakers 118 (http://austevol.files.wordpress.com/2013/09/aes-2013-program.pdf) and the data relating to talk 119 allocation (http://australasianevolutionsociety.com/ talk-selection-aes2013/) are publicly 120 available. 


\section{Analytical approach}

122 The conference delegates were categorised in four groups: student women, student men, 123 academic women, and academic men. 'Students' were defined as Honours, Masters or PhD 124 students, while 'academics' were defined as postdoctoral research associates, research fellows, 125 and all other academics. For each of the statistical analyses (described below) differences among 126 the four groups were assessed for each metric. Planned contrasts to directly compare student 127 women and men, and academic women and men, were carried out for each metric as women and 128 men at the same academic level should be comparable. The four plenary speakers were excluded 129 from all analyses as they did not have to decide what type of presentation to request, and were not 130 subject to the same selection procedures as other delegates. All statistical analyses were 131 performed in SAS version 9.3 for Windows 7 (64-bit).

We conducted five sets of analyses. First, we analysed whether there was any significant 133 difference from equal attendance by the four groups at the conference. This statistical test does 134 not tell us whether there is equal participation by each group because we do not know the true 135 distribution of Australasian evolutionary biologists in each of these groups. However, it does

136 indicate whether attendees walking around would have gained the "impression" that they were 137 observing each group evenly. To assess whether there was equal attendance among groups at the 138 conference, attendance ratio was tested in the SAS procedure FREQ using a chi-square test for 139 equal proportions, with exact p-values specified. Planned contrasts directly comparing student 140 men and women, and academic men and women, were carried out in SAS procedure FREQ by

141 testing for equal proportions in conference attendance using the binomial test. Two-sided p142 values were selected as we did not a priori predict that conference attendance would be higher in 143 one gender.

144 Second, we examined whether there was a difference among the four groups in 'exposure' 145 of their research, as measured by the average length of time each attendee spent in front of the 146 audience presenting their scientific research. We assigned an attendee who did not present the 147 exposure value '0 minutes', short-talk presenters '5 minutes', and long-talk presenters '12 148 minutes' presenting their research. Analysis of 'exposure' was carried out using two sets of data: 149 'exposure - all attendees', which were all 139 attendees including those who did not present (i.e., 150 including attendees who were assigned 0 mins); and 'exposure - presenters only', which only 151 included the 108 attendees who presented (i.e., excluding attendees assigned 0 mins). The 
152 'exposure - all attendees' metric is an attempt to coarsely represent the overall and general 153 impression of each group to other conference attendees. In contrast, the 'exposure - presenters 154 only' analysis may be more representative of the impression given to conference attendees who 155 only observed talks, without observing the ratios of each of these groups sitting around them in 156 the audience or during breaks; or to those conference attendees who entirely weighted their 157 impression of each group based on the presenters they saw, ignoring interactions they had when 158 outside the presentation sessions.

159 Analysis of both 'exposure' metrics was carried out using a Kruskal-Wallis non160 parametric one-way analysis of variance (ANOVA) using the SAS procedure NPAR1WAY with the 161 'Wilcoxon' option specified, where the response variable was 'exposure', and the independent 162 variable was 'group' (four categories as above). A non-parametric ANOVA was used because the 163 response variable 'exposure' can only have one of two or three values (0, 5, and 12 minutes), 164 therefore the data is not normally-distributed. The two-sample Kruskal-Wallis test statistic 165 produces p-values that are equivalent to two-sided p-values from a Wilcoxon two-sample rank166 sum test. Planned contrasts were used to directly compare 'exposure' for women and men within 167 each academic level.

168 Finally, we attempted to find the basis of any significant differences in 'exposure' by 169 analysing three metrics that reflected both the decisions of the attendees and any bias for or 170 against each group: preference to present a talk or not; of those choosing to give a talk, 171 preference for a long talk over a short talk; and, of those requesting a long talk, likelihood of 172 being assigned a long talk rather than a short talk. The first two metrics address the differences in 173 preferences for conference participation among the four groups, while the final question helps to 174 address any potential bias for or against the four groups.

175 For these three metrics, a likelihood ratio test in SAS procedure LoGISTIC was used to 176 assess for significant differences among groups by comparing the logit model with and without 177 the independent term 'group' (Agresti 2013). To assess whether there was a difference among 178 groups in their decision to present a talk (i.e., whether they submitted an abstract), the response 179 variable was 'present talk' (categorical: 'yes' or 'no'). To test whether there was a difference 180 among groups in their preference for a long talk over a short talk, only the subset of attendees 181 who chose to present a talk was analysed and the response variable was 'preference for long talk' 182 (categorical: 'yes' or 'no'). Finally, to assess whether there was a difference among groups in the 
183 likelihood of receiving a long talk when requested, only the subset of attendees who requested a

184 long talk in their conference registration was analysed and the response variable was 'received

185 long talk' (categorical: 'yes' or 'no'). For all analyses, planned contrasts were also carried out by

186 restricting the data to directly examine gender differences within each academic level (student

187 and academic).

\section{Results}

\section{Is there a difference among groups in attendance?}

190 There was no significant difference in attendance across the four groups (exact Chi-square test for 191 equal proportions: $\chi^{2}=4.17$, $\mathrm{df}=3$, exact $\mathrm{P}=0.245$; Table 1). Furthermore, student men and 192 women did not differ in their attendance ratio at the conference (binomial test for equal 193 proportions: $\mathrm{z}=1.48, \mathrm{df}=1$, two-tailed $\mathrm{P}=0.140$ ), and nor did academic women and men 194 (binomial test for equal proportions: $\mathrm{z}=-1.29, \mathrm{df}=1$, two-tailed $\mathrm{P}=0.198$ ).

\section{Is there a difference among groups in the amount of exposure to their colleagues?}

196 When considering all conference attendees, including those who did not present, there was no 197 significant difference in the amount of time the four groups spent presenting their research to 198 their colleagues (Kruskal-Wallis one-way analysis of variance (ANOVA) on 'exposure - all 199 attendees': $\chi^{2}=7.03, \mathrm{df}=3, \mathrm{P}=0.071$; Figure 1a), although it came close to significance. 200 However, when considering the two academic levels separately, student women spent a highly 201 significantly shorter period of time (36\% shorter: average of 5.9 mins vs 9.1 mins) presenting 202 their research to their colleagues than did student men (Kruskal-Wallis one-way ANOVA on 203 'exposure - all attendees': $\chi^{2}=7.44, \mathrm{df}=1, \mathrm{P}=0.006$; Figure 1a). On the other hand, academic 204 men and women did not differ in the amount of time (average of 7.4 mins vs 7.3 mins) spent 205 presenting their research (Kruskal-Wallis one-way ANOVA on 'exposure - all attendees': $\chi^{2}<$ $2060.01, \mathrm{df}=1, \mathrm{P}=0.995 ;$ Figure 1a).

207 Differences in 'exposure' among groups were exacerbated when considering only those 208 delegates who chose to present, with a significant difference among the groups in presentation 
209 time (Kruskal-Wallis one-way ANOVA on 'exposure - presenters only': $\chi^{2}=11.28$, df $=3, \mathrm{P}=$

210 0.010; Figure 1b). These differences among groups occurred at both the student and academic

211 level, and in the same direction. Of the students presenting, student women spent significantly

212 less time (23\% shorter: average of 7.9 mins vs 10.3 mins) presenting their research than student

213 men (Kruskal-Wallis one-way ANOVA on 'exposure - presenters only': $\chi^{2}=5.93$, df $=1, \mathrm{P}=$

2140.015 , Figure 1b). Of the academics presenting, academic women also spent significantly less

215 time (17\% shorter: average of 8.8 mins vs $10.6 \mathrm{mins})$ presenting their research than academic 216 men (Kruskal-Wallis one-way ANOVA on 'exposure - presenters only': $\chi^{2}=3.96$, df $=1, \mathrm{P}=$ 2170.047 , Figure 1b).

\section{Is there a difference among groups in preference for presenting a talk?}

219 There was no significant difference across the four groups in preference for presenting a talk 220 (likelihood ratio (LR) test for logit model: $\chi^{2}=4.93, \mathrm{df}=3, \mathrm{P}=0.177$; Table 1; Figure 2a), and 221 equivalent patterns were found when directly comparing within academic levels (LR test for logit 222 model: women vs men students: $\chi^{2}=2.25$, $\mathrm{df}=1, \mathrm{P}=0.133$; women vs. men academics: $\chi^{2}=$ $2232.18, \mathrm{df}=1, \mathrm{P}=0.140$; Figure $2 \mathrm{a})$.

224 Given the lack of difference among groups in preference for presenting a talk, the 225 difference in exposure between genders seen above is predominantly due to giving a long vs. a 226 short talk. Only 41\% (12/29) of presenting women students gave a long talk, as opposed to $75 \%$ 227 (18/24) of presenting men students. Similarly, only 54\% (14/26) of presenting academic women 228 gave a long talk, compared to 79\% (23/29) of academic men. Below we tease apart what caused 229 these differences between the genders in presenting long talks.

230 Of those choosing to give a talk, is there a difference among groups in preference for a long 231 talk over a short talk?

232 Of those presenting a talk, there was a significant difference among groups in their preference for 233 a long talk over a short talk (LR test for logit model: $\chi^{2}=9.55, \mathrm{df}=3, \mathrm{P}=0.023$; Table 1; Figure 234 2b). Student men tended to have a greater preference for a long talk over a short talk than student 235 women, although the difference was not significant and is based on a relatively low sample size 
236 (LR test for logit model: $\chi^{2}=3.03$, $\mathrm{df}=1, \mathrm{P}=0.082$; Figure $2 \mathrm{~b}$ ). At the academic level this is

237 shown much more clearly: academic men were significantly more likely to prefer a long talk over 238 a short talk compared to academic women (LR test for logit model: $\chi^{2}=6.22, \mathrm{df}=1, \mathrm{P}=0.013$; 239 Figure 2b).

240 Of those preferring a long talk over a short talk, is there a difference among groups in 241 likelihood of being assigned a long talk?

242 Of the attendees who preferred a long talk, there was no significant difference among the four 243 groups in the likelihood of the conference organisation committee assigning them a long talk (LR 244 test for logit model: $\chi^{2}=4.44, \mathrm{df}=3, \mathrm{P}=0.218$; Table 1; Figure 2c). However, student women 245 tended to be less likely than student men to be assigned a long talk when requested, although this 246 difference was not quite significant and is based on a relatively low sample size (LR test for logit 247 model: $\chi^{2}=3.20, \mathrm{df}=1, \mathrm{P}=0.074$; Figure $2 \mathrm{c}$ ). There was no significant difference between 248 academic women and men in the likelihood of being assigned a long talk when requested (LR test 249 for logit model: $\chi^{2}<0.01, \mathrm{df}=1, \mathrm{P}=0.926$; Figure 2c).

250 Relative importance of factors contributing to decreased exposure for women presenters

251 Above, we found that student women who chose to present had 23\% less time presenting than 252 student men. No single factor was responsible, with both weaker preference for a long talk and 253 allocation bias of a long talk being marginally non-significant contributors. If student women had 254 the same preference for a long talk as student men (but allocation for long talks did not change), 255 student women presenters would have 13.3\% less time presenting than student men (as opposed 256 to the $23 \%$ observed). An almost identical $13.1 \%$ difference in women student presenting time 257 would be achieved if allocation for long talks was equal to men students (but preference for long 258 talks did not change). This highlights that for women students, both talk preference and talk 259 allocation contribute equally to their reduced conference visibility as compared to men students.

260 In contrast, the $17 \%$ less time spent presenting by academic women compared to 261 academic men was almost solely due to a single factor: preference for a long talk. If academic 262 women had the same preference as academic men for a long talk (but allocation for long talks did 
263 not change), academic women presenters would only have $0.6 \%$ less presentation time than 264 academic men (as opposed to the 17\% observed). If allocation for long talks for academic women 265 was equal to academic men (but preference for long talks does not change) they would still be 266 presenting for $16.5 \%$ less time.

\section{Discussion}

268 We found that women spent significantly less time presenting their research at the 2013 269 Australasian Evolution Society conference compared to men. This discrepancy was driven 270 primarily by a stronger preference by men (or a weaker preference by women) for long talks. Our 271 results highlight that, even marginal, differences in the presentation strategy used by women and 272 men result in significantly different outcomes for exposure and visibility. Our results correspond 273 with previous research exploring gender differences in conference presentations decisions (Isbell, 274 Young and Harcourt 2012), which showed men had a stronger preference than women for 275 presenting a talk over a poster.

276 These data raise two interesting questions: (1) why do women and men have apparently 277 different presentation strategies, and (2) does this difference in presentation approach affect a 278 scientist's visibility and perception by colleagues (i.e., do these differences matter)? These 279 questions are pertinent to the broader issue of gender discrepancies in science, and will be 280 important to address as we move toward resolving the multitude of underlying reasons promoting 281 them.

282 Gender differences are apparent in a range of academic tasks. Women are more likely to 283 use tentative language when presenting their research (Leaper and Robnett 2011), reject 284 invitations to speak (Schroeder, Dugdale, Radersma et al. 2013), prioritize teaching over research 285 (Winslow 2010), are less likely to cite their own work (Maliniak, Powers and Walter 2013) or 286 have a webpage (Barjak 2006) when compared to men of equal career stage. Each of these 287 approaches or strategies may result in reduced visibility for women scientists, and ultimately may 288 contribute to and exacerbate the pre-existing gender imbalance.

289 The overall gender balance at the Australasian Evolution Society conference (2013) in 290 terms of attendance and participation in talks for both students and academics was not 291 significantly different from equal (c.f. Schroeder et al. 2013). This is encouraging for the future 
292 of evolutionary biology as a field and is reflective of a society that is acutely aware of the need to 293 promote gender balance. What is startling is that, while delegates at the conference would have 294 encountered equal numbers of women and men delegates, there remained a consistent gender bias 295 in the nature of talk preference, which led to an overall difference in the exposure and visibility 296 of women and men presenters (sensu Schroeder et al 2013). Student women engaged in 297 significantly less time presenting their research to colleagues than student men (Figure 1). This 298 amounted to 23 or $36 \%$ (equating to approximately 2 or 3 minutes on average) less exposure on 299 average for student women compared to student men, depending on whether you considered only 300 those who presented or student attendees overall, respectively. Although the number of academic 301 women attending did not differ overall from academic men, when considering only those who 302 presented, academic women as a population also spent significantly less time presenting their 303 work (Figure 1b): on average academic women presenters spent $17 \%$ less time presenting their 304 research than academic men.

305 We found that these differences in time spent speaking predominantly arose as a result of 306 gender bias in preference for long talks over short talks. Student and academic men had a 307 significantly higher preference for long talks than women presenters of the same level (Figure 308 1c), with a greater percentage of women choosing to present short 'speed' talks than their 309 equivalent men colleagues. By their very nature, short talks allow less detailed and 310 comprehensive presentation of scientific research than long talks. Therefore, by choosing to 311 present short talks women presenters may be portraying their scientific research and skill sets less 312 comprehensively than men at an equivalent stage.

313 Why were women less likely than men to request a long talk? That the patterns were 314 almost identical between student and academic women suggests that there is some inherent 315 gender difference and that the observed patterns are not influenced by which women survive the 316 leaky pipeline. We offer three reasons for the potential differences in presentation choices. First, 317 it is conceivable that the student and academic women were on average more junior than men in 318 the same category. Junior students would be more likely to present preliminary research or their 319 proposed research plan, and therefore be likely to choose (and be advised to choose) a short talk.

320 This is compared to students in their final year of $\mathrm{PhD}$ research, who would be presenting long 321 and comprehensive talks to cover their research outcomes, and in order to increase their chances 322 of securing post-doctoral research opportunities in the near future. Similarly, junior academics, 323 especially those on short-term research contracts, may be more likely to present short talks as 
324 they are more likely than established researchers to have recently changed jobs and/or research 325 area and so have preliminary data more suited to a short talk. A coarse examination of our data 326 suggested that, within the academics, the patterns were comparable for postdoctoral fellows and 327 tenured staff. However, due to the sample size and incomplete information, we were not able to 328 analyse this formally. Analysing the academic levels more finely, such as incorporating the

329 'academic age' of all conference attendees, would be particularly valuable in ruling in or out this 330 possible explanation for our observed gender bias.

331 Second, women may tend to be less aware than men of the value of presenting their 332 research comprehensively, or may receive less encouragement or mentorship from supervisors to 333 do so (Sambunjak, Straus and Marušić 2006). Women may even consider a short amount of 334 visibility on a less comprehensive piece of research as more valuable than less frequent but more 335 comprehensive visibility, while men may value the opposite strategy. There is some evidence in 336 our data to support this latter argument (Figure $2 \mathrm{a}$ and $2 \mathrm{~b}$ ): fewer academic men requested a 337 presentation than women ( $69 \%$ vs. $84 \%$ ) but when they did so they had a significantly stronger 338 preference for long talks ( $90 \%$ vs. $62 \%)$ than academic women.

339 Third, women have previously been shown to be more risk averse and thus more reticent 340 to publicise their research (Maliniak, Powers and Walter 2013) particularly if they believed it was 341 at an incomplete stage. If true, this might easily translate into a reluctance to publish thus 342 reducing publication output (a highly valued metric of productivity and often researcher quality) 343 even from an early career stage. Such risk aversion may provide one explanation for the 344 'productivity puzzle' identified across so many fields of academia (Xie and Shauman 1998, 345 Symonds, Gemmell, Braisher et al. 2006).

346 Gender differences in self-perception are apparent in other dimensions of academic 347 output. While a weaker preference for long over short talks, or talks over posters (Isbell, Young 348 and Harcourt 2012) at conferences and a reduction in the incidence of self-citation might reflect a 349 real difference in how women "play the academic game", both strategies lead to a reduction in 350 the visibility of women at all stages of their academic career. The broader impact for senior 351 researchers of refusing plenary invitations was comprehensively outlined by Schroeder et al 352 (2013). Without doubt, under-representation and lower visibility of women scientists at more 353 senior levels may serve as a negative influence on their junior colleagues, perpetuating the 354 tendency for women to leave academia post-PhD. Our data suggests that many of the issues 
355 surrounding gender differences in visibility are already present at the junior level and a possible

356 reason for these differences is a lack of awareness of the consequences of under-promoting 357 yourself.

358 The selection process for the AES conference was not conducted entirely blind to gender 359 (names were known, but gender was unspecified), and we found some evidence (albeit 360 constrained by small sample sizes) that student women were less likely to be assigned a higher 361 visibility long-talk slot than student men. In a recent paper, Knobloch-Westerwick et al. (2013) 362 assessed experimentally the effect of gender on the perceived quality of conference abstracts. 363 Abstracts allocated a 'male author' were deemed of greater 'scientific quality' than those 364 allocated a 'female author'. Perhaps more interestingly, was that less than a quarter of the 365 participants assessing the abstracts could actually recall the gender of the abstract authors. This 366 suggests that the observed differences arose through subconscious bias or "processes that the 367 participants were unaware of and did not invest much cognitive capacity in" (Knobloch368 Westerwick, Glynn and Huge 2013).

369 Future directions

370 Additional studies are needed to understand whether these results are representative of the 371 broader scientific community. However, our findings contribute to a growing body of literature 372 (Leaper and Robnett 2011, Schroeder, Dugdale, Radersma et al. 2013) that raises several 373 interesting questions about why men and women adopt different strategies for presenting their 374 research at conferences. Future studies should seek to tease apart the factors driving this gender 375 difference both in terms of presenters' choices (e.g., advice from supervisors or colleagues, stage 376 in career, perceived value of presentation, insecurity or risk-aversion), and the selection 377 committee's choices (e.g. whether the perceived gender of the author or the wording of their 378 abstracts affects talk allocation decisions).

379 We offer four strategies for future conferences that may help redress the above imbalance.

380 First, greater effort should be made to educate both supervisors and students about innate gender

381 differences in behaviour and how these may exacerbate gender disparity in academia.

382 Historically, most attempts to address gender discrepancies in the workplace have focused on 383 discrimination by others. However, there has been considerably less focus on how gender 
384 differences in behaviour can impact professional performance (Schroeder et al 2013). By 385 explicitly recognizing these behavioural differences, women will be better equipped to evaluate 386 their own decisions, and mentors may be better able to offer advice about how to improve 387 performance and be more competitive. Failure to recognize and educate people about these 388 gender differences makes it more challenging to level the playing field for women and men and 389 narrow the gender gap in academia and other fields of life. In the specific case of conferences, 390 mentoring should highlight that, while it is tempting to view conference presentations as 'less 391 important' than perhaps publishing a manuscript, acceptance at a conference may have

392 implications for a future career that extends far beyond the single five- or twelve-minute 393 presentation slot. Second, the language used by conference organisers when inviting submission 394 of abstracts should be reviewed as it may discourage women from submitting abstracts for 395 particular presentation types (Born and Taris 2010). In particular, requests for talks that present 396 clear and unambiguous results ('no speculative abstracts') may bias submissions of longer and 397 more comprehensive talks towards men rather than women, particularly if there is a gender 398 difference in the level of self-doubt about their results. Third, to redress any potential for 399 subconscious gender bias in assessment of conference abstracts, all abstracts (for all conferences) 400 should, at the very least, be scored blind with respect to gender, as is the case for an increasing 401 number of journals (Engqvist and Frommen 2008). Finally, and admittedly somewhat self402 promotionally, to raise awareness of the potential pitfalls associated with reduced visibility and 403 exposure we suggest that societies and particularly conference organisers could provide links to 404 manuscripts and documents that highlight potential gender differences and their implications.

\section{Conclusions}

406 Here we report a striking difference in visibility of men and women at the 2013 407 Australasian Evolution Society conference. Similar numbers of men and women attended the 408 conference, and there was no gender difference in the decision to present (i.e., submit an 409 abstract). However, women presenters spent on average $\sim 20 \%$ less time presenting their research 410 than men. This discrepancy was driven by gender differences in talk preference: men's preference 411 for long talks over short talks was stronger than women's preference. This highlights important 412 gender differences in conference strategy, and merits further attention in order to understand how 413 this may contribute to gender disparities in academia. 
414 While conference abstracts are generally not regarded as research outputs in the field of 415 behavioural and evolutionary biology, conference attendance and presentations (particularly 416 plenary presentations) are important means by which scientists are assessed (Schroeder, Dugdale, 417 Radersma et al. 2013). Typically, care is taken to reduce the Matilda effect by ensuring equity, if 418 not parity, at the invited plenary level (as indeed was the case for the AES conference). However, 419 if women are less likely to request presentations with a perceived higher value, this is highly 420 problematic. The result is not only a reduction in their immediate visibility but it may have 421 significant implications for future funding opportunities and publication success.

\section{Acknowledgements}

423 We would like to thank Rob Brooks, Lee Ann Rollins, and Ben Fanson for early discussion.

\section{References}

425 Agresti, A (2013). Categorical data analysis. New Jersey, John Wiley \& Son.

426 Barjak, F (2006). The role of the Internet in informal scholarly communication. Journal of the 427 American Society for Information Science and Technology 57(10): 1350-1367.

428 Born, MP and TW Taris (2010). The impact of the wording of employment advertisements on 429 students' inclination to apply for a Job. Journal of Social Psychology 150(5): 485-502.

430 Bornmann, L and HD Daniel (2005). Selection of research fellowship recipients by committee 431 peer review. Reliability, fairness and predictive validity of Board of Trustees' decisions. 432 Scientometrics 63(2): 297-320.

433 Casadevall, A and J Handelsman (2014). The presence of female conveners correlates with a 434 higher proportion of female speakers at scientific symposia. mBio 5(1).

435 Conley, D and J Stadmark (2012). Gender matters: A call to commission more women writers. $436 \quad$ Nature 488(7413): 590.

437 Damschen, EI, KM Rosenfeld, M Wyer, D Murphy-Medley, TR Wentworth and NM Haddad 438 (2005). Visibility matters: increasing knowledge of women's contributions to ecology. 439 Frontiers in Ecology and the Environment 3(4): 212-219.

440 Davenport, E and H Snyder (1995). Who cites women? Whom do women cite? An exploration of 441 gender and scholarly citation in sociology. Journal of Documentation 51(4): 404-410. 
442 Engqvist, L and JG Frommen (2008). Double-blind peer review and gender publication bias. 443 Animal Behaviour 76: E1-E2.

444 Faulkner, W (2009). Doing gender in engineering workplace cultures. II. Gender in/authenticity 445 and the in/visibility paradox. Engineering Studies 1(3): 169-189.

446 Ferber, MA and M Brun (2011). The gender gap in citations: does it persist? Feminist Economics 447 17(1): 151-158.

448 Hill, C, C Corbett and A St Rose (2010). Why so few? Women in Science, Technology, 449 Engineering, and Mathematics. Washington, AAUW.

450 Isbell, LA, TP Young and AH Harcourt (2012). Stag parties linger: continued gender bias in a 451 female-rich scientific discipline. Plos One 7(11).

452 Knobloch-Westerwick, S, CJ Glynn and M Huge (2013). The Matilda effect in science 453 communication: an experiment on gender bias in publication quality perceptions and 454 collaboration interest. Science Communication 35(5): 603-625.

455 Kretschmer, H, R Kundra, DD Beaver and T Kretschmer (2012). Gender bias in journals of 456 gender studies. Scientometrics 93(1): 135-150.

457 Larivière, V, C Ni, Y Gingras, B Cronin and CR Sugimoto (2013). Global gender disparities in 458 science. Nature 211: 211-213.

459 Leaper, C and RD Robnett (2011). Women are more likely than men to use tentative language, 460 aren't they? A meta-analysis testing for gender differences and moderators. Psychology of 461 Women Quarterly 35(1): 129-142.

462 Lincoln, AE, S Pincus, JB Koster and PS Leboy (2012). The Matilda Effect in science: Awards 463 and prizes in the US, 1990s and 2000s. Social Studies of Science 42(2): 307-320.

464 Maliniak, D, R Powers and BF Walter (2013). The gender citation gap in international relations. 465 International Organization 67: 889-922.

466 Moss-Racusin, CA, JF Dovidio, VL Brescoll, MJ Graham and J Handelsman (2012). Science 467 faculty's subtle gender biases favor male students. Proceedings of the National Academy of 468 Sciences 109(41): 16474-16479.

469 Pell, AN (1996). Fixing the leaky pipeline: Women scientists in academia. Journal of Animal $470 \quad$ Science 74(11): 2843-2848.

471 Rossiter, MW (1993). The Matthew-Matilda Effect in Science. Social Studies of Science 23(2): $472 \quad 325-341$.

473 Sambunjak, D, SE Straus and A Marušić (2006). Mentoring in academic medicine: a systematic 474 review. Journal of the American Medical Association 296: 1103-1115. . 
475 Schroeder, J, HL Dugdale, R Radersma, M Hinsch, DM Buehler, J Saul, L Porter, A Liker, I De 476 Cauwer, PJ Johnson, AW Santure, AS Griffin, E Bolund, L Ross, TJ Webb, PGD Feulner, I 477 Winney, M Szulkin, J Komdeur, MA Versteegh, CK Hemelrijk, EI Svensson, H Edwards, M 478 Karlsson, SA West, ELB Barrett, DS Richardson, V van den Brink, JH Wimpenny, SA 479 Ellwood, M Rees, KD Matson, A Charmantier, N dos Remedios, NA Schneider, C Teplitsky, 480 WF Laurance, RK Butlin and NPC Horrocks (2013). Fewer invited talks by women in 481 evolutionary biology symposia. Journal of Evolutionary Biology 26(9): 2063-2069.

482 Symonds, MRE, NJ Gemmell, TL Braisher, KL Gorringe and MA Elgar (2006). Gender 483 differences in publication output: towards an unbiased metric of research performance. Plos 484 One 1(2).

485 Thelwall, M, F Barjak and H Kretschmer (2006). Web links and gender in science: An 486 exploratory analysis. Scientometrics 67(3): 373-383.

487 Tinsley, CH, SI Cheldelin, AK Schneider and ET Amanatullah (2009). Women at the bargaining 488 table: Pitfalls and prospects. Negotiation Journal 25(2): 233-248.

489 Wenneras, C and A Wold (1997). Nepotism and sexism in peer-review. Nature 387(6631): 341490343.

491 West, JD, J Jacquet, MM King, SJ Correll and CT Bergstrom (2012). The role of gender in 492 scholarly authorship. arXiv preprint arXiv:1211.1759.

493 Winkler, JA, D Tucker and AK Smith (1996). Salaries and advancement of women faculty in 494 atmospheric science: Some reasons for concern. Bulletin of the American Meteorological 495 Society 77(3): 473-490.

496 Winslow, S (2010). Gender inequality and time allocations among academic faculty. Gender \& 497 Society 24(6): 769-793.

498 Xie, Y and KA Shauman (1998). Sex differences in research productivity: New evidence about an 499 old puzzle. American Sociological Review 63(6): 847-870. 
500 Table 1. Participation in talk presentations at the AES conference for the groups represented by 501 student and academic women and men. The four invited plenary speakers (two women; two 502 men) are not included.

\begin{tabular}{|c|c|c|c|c|c|c|c|c|c|c|c|}
\hline \multirow{2}{*}{$\begin{array}{l}\text { Academic } \\
\text { Level }\end{array}$} & \multirow{2}{*}{ Gender } & \multirow{2}{*}{ Attending } & \multicolumn{3}{|c|}{ Presenting } & \multicolumn{3}{|c|}{ Requested Long Talk } & \multicolumn{3}{|c|}{ Received Long Talk } \\
\hline & & & Yes & No & $\%$ Yes & Yes & No & $\%$ Yes & Yes & No & $\%$ Yes \\
\hline \multirow[t]{2}{*}{$\overline{\overline{\text { Student }}}$} & Women & 39 & 29 & 10 & $7474 \%$ & 18 & 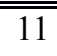 & $62 \%$ & 12 & 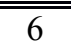 & $67 \%$ \\
\hline & Men & 27 & 24 & 3 & $89 \%$ & 20 & 4 & $83 \%$ & 18 & 2 & $90 \%$ \\
\hline \multirow[t]{2}{*}{ Academic } & Women & 31 & 26 & 5 & $84 \%$ & 16 & 10 & $62 \%$ & 14 & 2 & $88 \%$ \\
\hline & Men & 42 & 29 & 13 & $69 \%$ & 26 & 3 & $90 \%$ & 23 & 3 & $88 \%$ \\
\hline
\end{tabular}



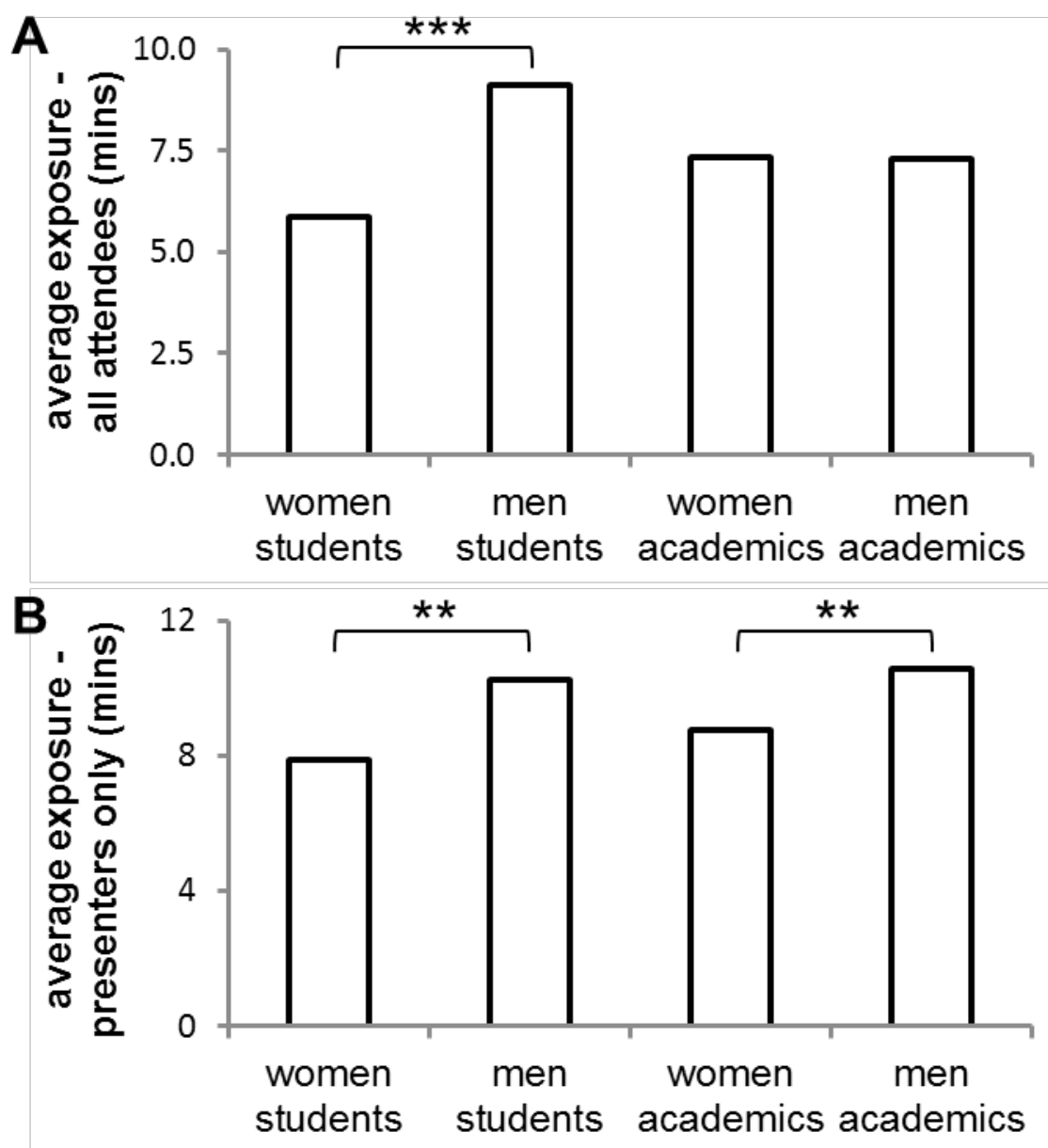

503 Figure 1. Average time (minutes) spent presenting scientific research ('exposure') for student and

504 academic women and men at the AES conference. A: Exposure of all attendees. This average also 505 includes attendees who did not present a talk and so may reflect an impression of an observer

506 who attends and weights their impression by all aspects of the conference. B: Exposure of 507 presenters only. This average includes only those attendees who presented a talk and so may 508 reflect the impression of an observer who only observes the talk presenters and gauges no other 509 impression from the audience around them, or else weights their impression of each group solely 510 based on presenters. Significance values of planned contrasts: ** $\mathrm{P}<0.05 ; * * * \mathrm{P}<0.01$. 


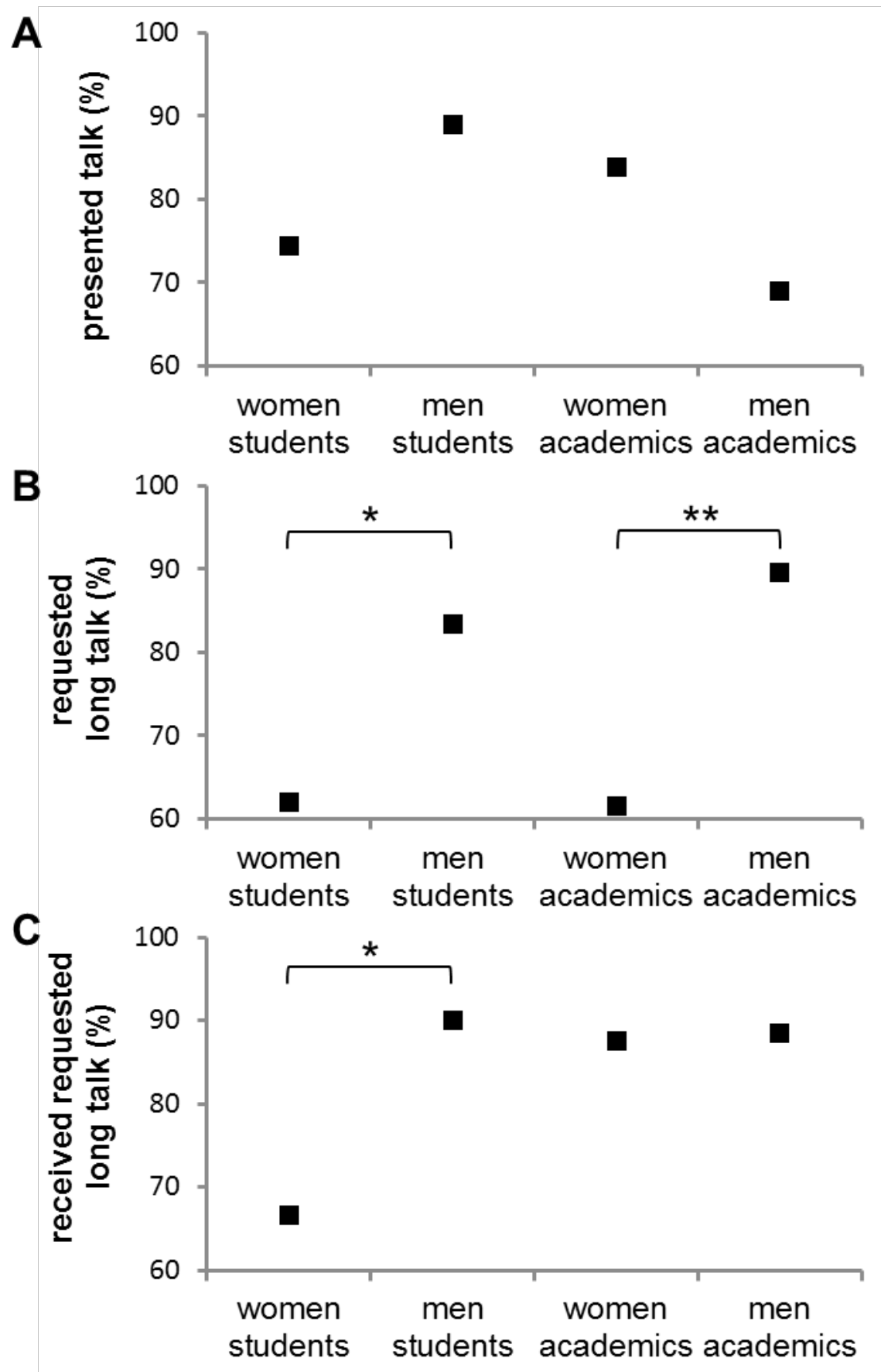

511 Figure 2. Comparing participation of student and academic women and men at the AES 512 conference. A: Percentage choosing to present a talk. B: Of those choosing to present a talk, 513 percentage who prefer a long talk over a short talk. C: Of those who prefer a long talk over a 514 short talk, percentage of those who were assigned a long talk. Significance values of planned 515 contrasts: * $\mathrm{P}<0.1 ; * * \mathrm{P}<0.05$. 


\section{Figure 1}

Time spent presenting at the AES conference

Average time (minutes) spent presenting scientific research ('exposure') for student and academic women and men at the AES conference. A: Exposure of all attendees. This average also includes attendees who did not present a talk and so may reflect an impression of an observer who attends and weights their impression by all aspects of the conference. B: Exposure of presenters only. This average includes only those attendees who presented a talk and so may reflect the impression of an observer who only observes the talk presenters and gauges no other impression from the audience around them, or else weights their impression of each group solely based on presenters. Significance values of planned contrasts: ${ }^{* \star} P<0.05 ;{ }^{* \star *} P<0.01$. 
PeerJ Reviewing Manuscript
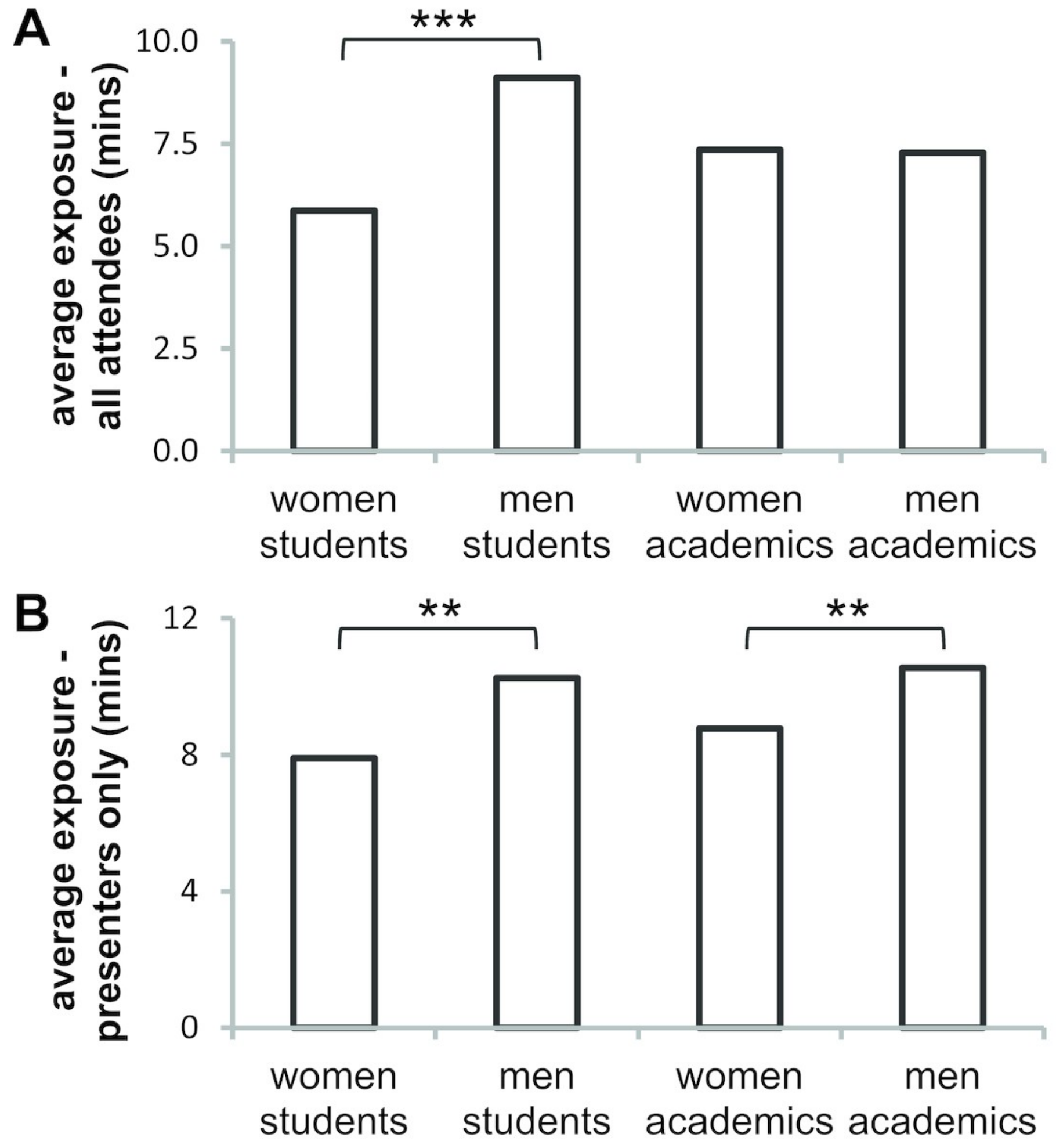


\section{Figure 2}

Participation at the AES conference

Comparing participation of student and academic women and men at the AES conference. A:

Percentage choosing to present a talk. B: Of those choosing to present a talk, percentage who prefer a long talk over a short talk. C: Of those who prefer a long talk over a short talk, percentage of those who were assigned a long talk. Significance values of planned contrasts:

${ }^{*} \mathrm{P}<0.1 ;{ }^{*} \mathrm{P}<0.05$. 
A

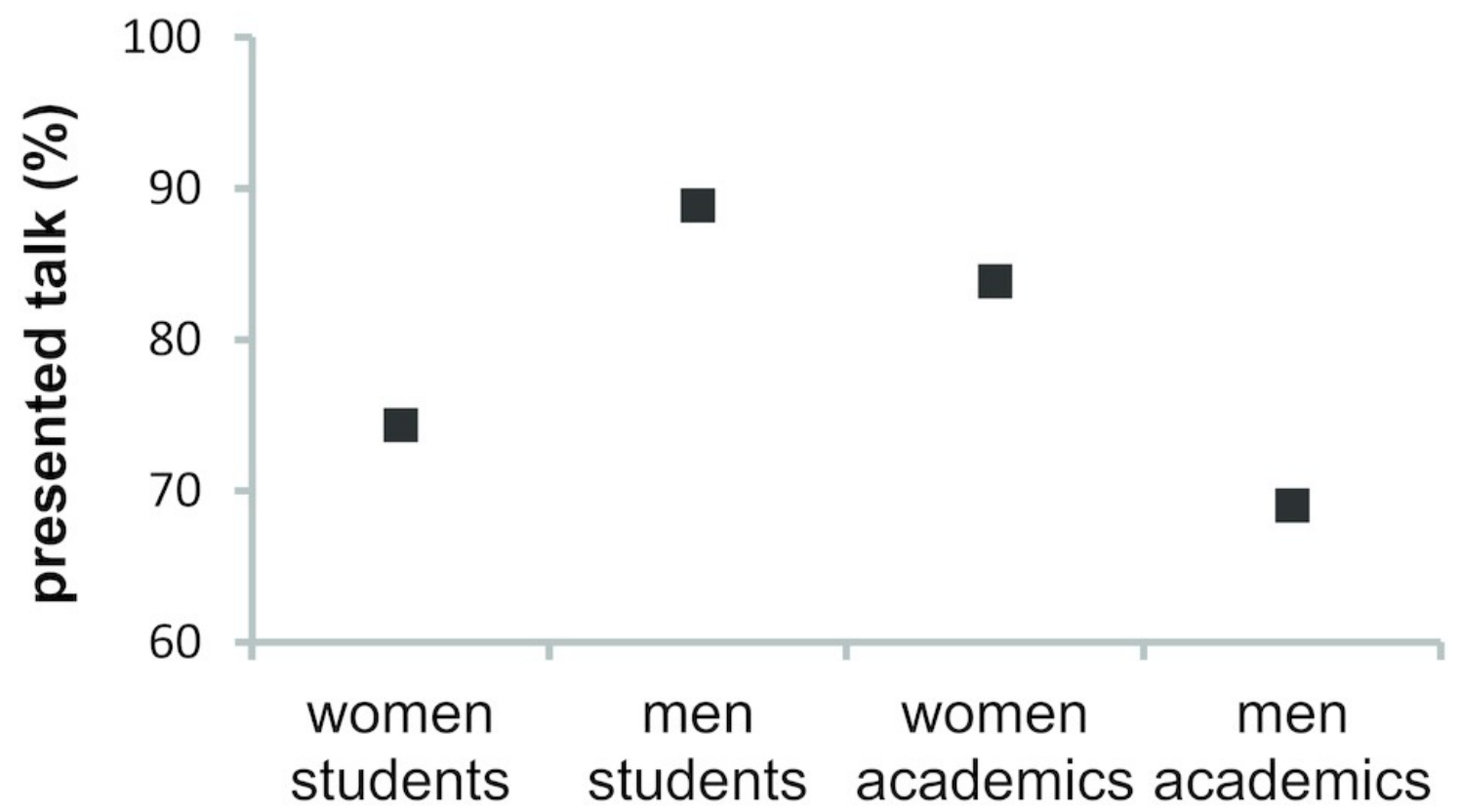

B

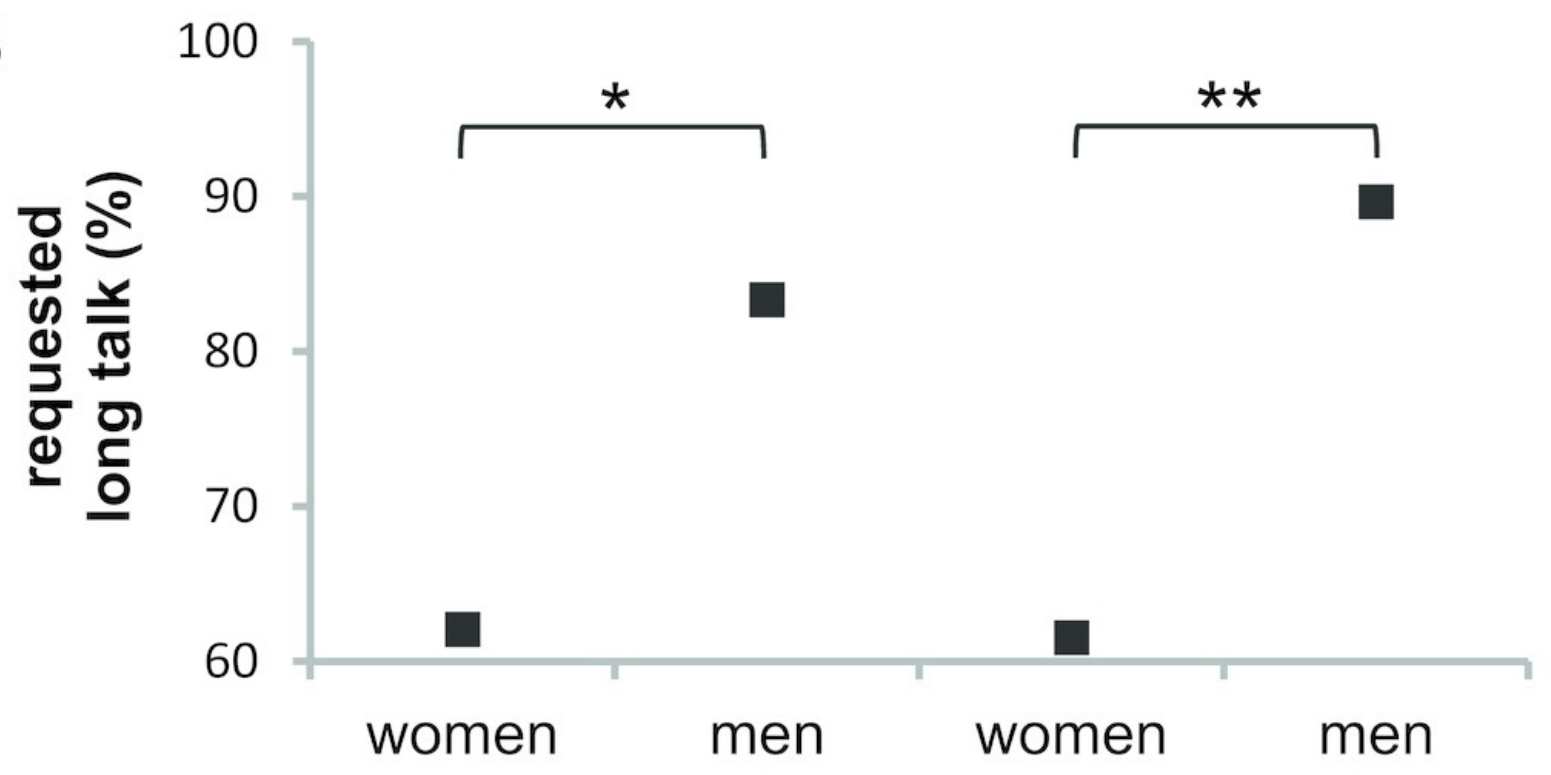

students students academics academics

C

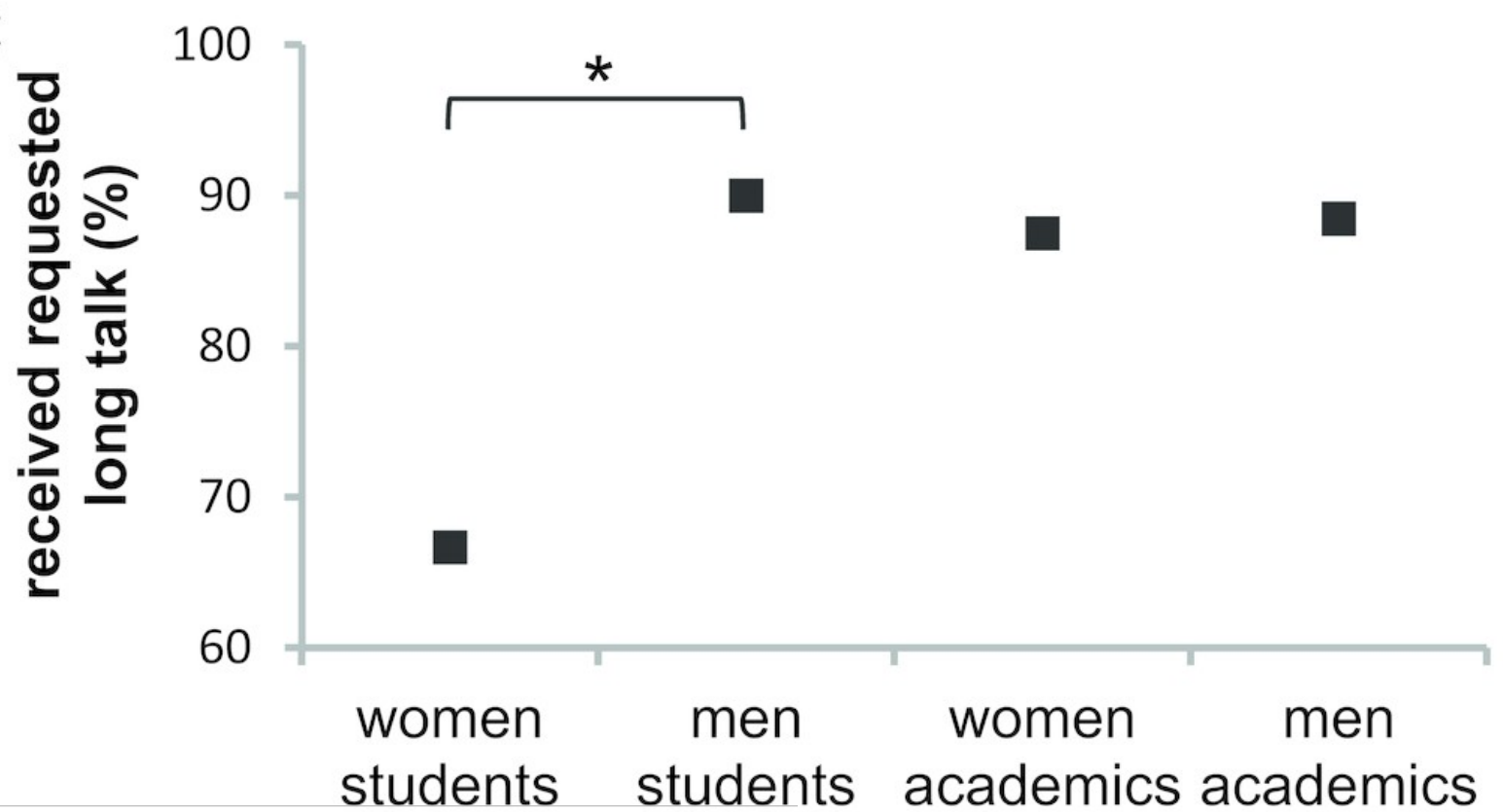




\section{Table 1 (on next page)}

Table of statistics for attendees to the AES conference 


\section{PeerJ Reviewing Manuscript}

1Table 1. Participation in talk presentations at the AES conference for the groups represented

2 by student and academic women and men. The four invited plenary speakers (two women;

3 two men) are not included.

\begin{tabular}{|c|c|c|c|c|c|c|c|c|c|c|c|}
\hline \multirow{2}{*}{$\begin{array}{l}\text { Academic } \\
\text { Level }\end{array}$} & \multirow{2}{*}{ Gender } & \multirow{2}{*}{ Attending } & \multicolumn{3}{|c|}{ Presenting } & \multicolumn{3}{|c|}{ Requested Long Talk } & \multicolumn{3}{|c|}{ Received Long Talk } \\
\hline & & & Yes & No & $\%$ Yes & Yes & No & $\%$ Yes & Yes & No & $\%$ Yes \\
\hline \multirow[t]{2}{*}{$\overline{\text { Student }}$} & Women & 39 & 29 & 10 & $74 \%$ & 18 & 11 & $62 \%$ & 12 & $\overline{6} 6$ & $67 \%$ \\
\hline & Men & 27 & 24 & 3 & $89 \%$ & 20 & 4 & $83 \%$ & 18 & 2 & $90 \%$ \\
\hline \multirow[t]{2}{*}{ Academic } & Women & 31 & 26 & 5 & $84 \%$ & 16 & 10 & $62 \%$ & 14 & 2 & $88 \%$ \\
\hline & Men & 42 & 29 & 13 & $69 \%$ & 26 & 3 & $90 \%$ & 23 & 3 & $88 \%$ \\
\hline
\end{tabular}

